\title{
PATIENT WITH MAJOR ENDOGENOUS DEPRESSIVE EPISODE WITH SUICIDE ATTEMPT
}

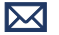 \\ ${ }^{1}$ Faculty of Psychology and Educational Science, University of Bucharest, Romania \\ Alex Obregia" Clinical Hospital for Psychiatry, Bucharest, Romania \\ "Carol Davila" University of Medicine and Pharmacy, Bucharest, Romania
}

Mariana Andruța Voicu ${ }^{1}$, Adriana Mavlea ${ }^{1}$, Ilinca Vlaicu ${ }^{1}$, Florin Mititelu ${ }^{2}$ and Simona Trifu ${ }^{3}$
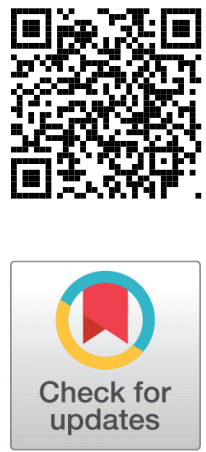

Received 28 April 2021

Accepted 18 May 2021

Published 31 May 2021

Corresponding Author

Simona Trifu, simona.trifu@umfcd

.ro

DOI $10.29121 /$

granthaalayah.v9.i5.2021.3925

Funding: This research received no specific grant from any funding agency in the public, commercial, or not-for-profit sectors.

Copyright: (C) 2021 The Author(s). This is an open access article distributed under the terms of the Creative Commons Attribution License, which permits unrestricted use, distribution, and reproduction in any medium, provided the original author and source are credited.

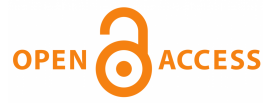

\section{ABSTRACT}

Motivation: Suicide is a major psychiatric emergency, men being more inclined to successful suicide, not to attempts and to approach it by abrupt and aggressive means.

Objectives: To present a male patient who developed a major depressive episode, in which the reactive component had a significant contribution in return for endogeny. The suicide attempt quickly escalated changes in thymic function over several days.

Results: The patient corresponds to the age at which major depressive disorder begins. There remains a clinical discussion between a genuine suicide attempt, carried out with a plan, internal turmoil, rumination or a parasuicide, in which the person in question needed a change in the field of consciousness to try to throw himself in front of the subway. Note the high internal tension, the absence of the search for alternative solutions, the narcissistic wound, the endo-psychic vulnerability, the elements of correctness such as structural mental rigidity.

Conclusions: Early responsiveness to medication emphasizes the endogenous potential and the potential of vulnerability, after the approach through a combination of antidepressants and antipsychotics, the latter developing a clearer perspective on reality and decisions.

Keywords: Suicide, Twilight, Major Depressive Episode, Structural Intransigence, Vulnerability

\section{INTRODUCTION}

\subsection{BACKGROUND}

A 48-year-old patient presents for a check-up at the psychiatric office. He had a suicide attempt, after which he was urgently brought to the guard room and hospitalized 
on a non-voluntary basis. He confesses that he had another suicide attempt, but his plan was thwarted by his wife, who hid the drugs with which he intended to carry out his plan.

Heredocolateral antecedents: Not specified.

\subsection{MEDICAL HISTORY}

The patient does not have a psychiatric history with active hospitalizations, he can only recall having gone to a specialized consultation and receiving an antidepressant treatment which he did not follow.

The patient suffers from somatic diseases, 6 years ago he suffered a minor heart attack and is taking hypertension medication ever since.

Personal history: The patient attended a high school for optics, and after graduation he tried to enroll in two universities, but without success. Eventually, he was enrolled on the third attempt at the Faculty of Political Science. He was simultaneously working as an inspector at the Post Office where he also joined its trade union movement, becoming a union leader (still being one today). He did not continue with his undergraduate studies and never completed them.

He is married and has two children, a 14-year-old boy and a 9-year-old girl.

Relationships between him and his children: He is involved in their upbringing.

When his son was 5 years old, they brought him to a psychologist as he had developed fraternal jealousy when his sister was born. He describes him by saying "He does well in school (...) He is a child whose homework I have never had to check, he did everything himself. He has an average of 9 and he is on a scholarship."

About the daughter, he states that her temperament is the opposite of her brother's - "From the age of 1 she showed independence and stubbornness (...) As parents, we gave in every time." "She is very skilled; she knows how to negotiate. She is a person who is a little naive, she is still 9 years old, but she will definitely manage in life."

\subsection{THE RELATIONSHIP BETWEEN HIM AND HIS WIFE}

He confesses that the relationship between him and his wife gradually grew colder after the birth of their little girl who needed closeness from the mother, forcing the father to isolate in another room - "The relationship between daughter and mother is more special, fusional, more symbiotic. Yes, I left them because I thought it was for the good of the child, thinking that she would grow up and that my wife and I would get back to each other. But it never happened (...)

We had become two acquaintances (...) from time to time we met at night in the living room. "

The relationship between the two worsened when his wife lost her job. "My wife lost her job, she changed radically, being very affected by this ... At the same time, our relationship got even colder..." 
In the run-up to the suicide attempts, he confesses that he had become angry and irritable. "I became angry, irritable, with all kinds of problems at work (...) I was screaming at the children. My wife used to tell me that I scream all the time and that I don't talk to anyone anymore, I just scream."

He tried to see a psychologist in order to remedy his anger, but did not complete the process.

Eventually, his relationship with his wife deteriorated more and more and he declared that he wanted to separate from her "I had built a wall around myself and I was saying that I am tired and want to divorce."

He found out that his wife was cheating on him, but he decided not to separate from her. On the contrary, he took all the necessary steps to save the marriage. "I told her very clearly that I was going to fight for our marriage, that I will try to change everything that was wrong with me in our relationship so far. I can change, I can make our relationship continue"

This situation still hurt him "it hurt the most because it deceived my trust (...) In my strange way, I love her very much."

The couple's problems were ignored and denied out of a desire to stay with his wife. He always tried to find excuses for the couple having gone cold, so he explained that sleeping separately from his wife was because the little girl was in great need of her mother. This first alarm signal is normally the result of couple problems, a distance, an "erosion" over time. Neither partner made a sustained effort to get back together and to renew the intimate relationship. Both partners but especially the husband, hid the couple's problems behind the girl's refusal to sleep alone. In the same sense, he kept hoping that even if his wife cheated on him, their relationship would continue because he would be willing to forgive her and move on. The moment he realized that it was not just an adventure, and the relationship between them is about to end, was when he asked his wife if she loved the other man and her answer was "I don't know".

When asked if he ever cheated on his wife, he admits he did so three times. In all situations it was a temporary situation, never having been emotionally involved. This context gives rise to the hypothesis that he took refuge in physical contact, in the "bodily" part of a relationship, given the fact that he and his wife were no longer intimate. It is also suggested that he lacked self-confidence and the courage to go beyond the physiological need with a woman and create a relationship, precisely because he hoped that at some point, things would return to normal in marriage. At the same time, the lack of desire to attach could have arisen from the denial of the parallel relationship of the wife and the ignorance of the possibility that this is not just an adventure, as he was still fighting for his former life to come back "We went to concerts together, we were at the French Institute (...). We also saw our godparents, because we never saw anyone anymore, we had each isolated ourselves in our own ugly and crooked world ". 
Mentally, at the moment: he presents hyperprosexia on depressive ideas of guilt: "We had a very bad communication between us, many things could have been saved from what happened. Give the Romanian the last mind *expression* (....) I wanted to commit suicide because it was better for everyone".

The endogeneity or reactive context of the patient's major depressive episode was considered. Thus, the endogeneity hypothesis remains established with the arguments of a satisfactory and rapid response to medication. "I've never been so enlightened and calm. I feel good and I'm optimistic. I didn't think some chemicals could make you see reality more clearly."

The speech is fluent, the expression is easy, the vocabulary is vast, complex.

\section{MATERIALS AND METHODS}

In this article, we included details from psychiatric evaluation, psychiatric interview, psychodynamic interviews, and psychodynamic interpretations. The patient has benefited from psychiatric and psychological monitoring of the daily progression under treatment.

\section{RESULTS AND DISCUSSIONS}

\subsection{DIAGNOSIS}

The diagnosis is: major endogenous depressive episode in Bipolar II Affective Disorder

Diagnostic criteria according to DSM 5 (2013) is: hypo-maniacal episode

1. The patient had a well-defined period characterized by a persistently irritable mood, as well as activity aimed at the goal of divorcing his wife which lasted for at least 4 consecutive days, present for most of the day, almost daily. He wanted to go to a psychologist for anger management, but he failed to complete the process.

2. During mood swings and increased energy or activity, three (or more) of the following symptoms, (four if the mood is only irritable) persisted, represent a significant change from normal behaviour, and are present at a significant level:

- Exaggerated self-esteem or a sense of grandeur. "It just so happened that I became acquainted with the minister and he helped get her a job in the ministry."

- Decreased need for sleep (e.g., the individual feels rested after only three hours of sleep).

- The individual is more talkative than usual or has the pressure to speak; this aspect is not excluded.

- Running away from ideas or the subjective feeling of accelerating thinking.

- Distractibility (i.e., attention is easily captured by unimportant or irrelevant external stimuli), reported by patients, or observed by the people around them. 
It seems that his attention is fully captured when asked about the union, leaving aside the main topic. It is not excluded that he would be distractible at this time.

- Increasing activity aimed at a goal (either social, at work, or sexual) or psychomotor agitation. "I became angry, irascible, with all kinds of problems at work."

- Excessive involvement in activities with high potential to lead to unpleasant consequences (e.g., engaging in very expensive entertainment, inappropriate sexual behaviour, or reckless investment in business). He cheated on his wife three times, occasionally with different people.

3. The episode is associated with an unequivocal change in functioning, which is not characteristic of the individual when it is not symptomatic. "You don't talk to me anymore, you just yell at the kids and me (wife)" "Nothing was good enough for me anymore."

4. Alteration and change of operation are observed by the people around them. "You do everything you can to get a divorce, you've been telling everyone for months (wife).

5. The episode is not severe enough to cause a marked deficit in social and professional functioning or to require hospitalization. If psychotic elements are present, the

episode is by definition manic.The episode cannot be attributed to the physiological effects of a substance (e.g., an abuse drug, a drug, another treatment). [Association (2013) ]

\subsection{THE MAJOR DEPRESSIVE EPISODE}

A. Five or more of the following symptoms have been present during the same twoweek period and represent a change from previous functioning level, at least one of the symptoms being either (1) depressive mood or (2) loss of interest and pleasure.

1. Depressive mood most of the day, almost daily, either reported daily or subjectively reported by the individual (e.g., feelings of sadness, inner emptiness, or hopelessness), or observed by the people around them (e.g., crying easily). "I admit that I cried (...) If I died it would be better for everyone."

2. The marked decrease in interest and pleasure for all have for almost all activities, most of the day (either declared subjectively by the individual or observed by the people around). "I had built a wall; nothing was good enough for me anymore."

3. Significant weight loss without following a diet or weight gain (e.g., over 5\% change in body weight within one month), or decrease or increase appetite almost daily.

4. Insomnia or hypersomnia almost daily.

5. Psychomotor agitation or slowness almost daily (observed by the people around, not just the subjective feeling of restlessness or slowness).

6. Asthenia or loss of energy almost daily. 
7. Feelings of uselessness or exaggerated or inappropriate guilt (which can reach a psychotic level) almost daily (not just self-blame or guilt about the disease). "I'm soft when I shouldn't ... There were situations when trying to do good to someone, I also hurt myself (...) Many things could have been saved (...) I'm to blame ."

8. Decreased ability to think or concentrate, or indecision, almost daily (either declared subjectively by the individual or observed by the people around). He was undecided even on the day he wanted to commit suicide. Initially he wanted to go to his mother, after which he changed his mind.

Paradoxically, he left with two backpacks, in one he had clothes, to stay with his mother for a few days then move, overcome the moment and choose life, and in the other backpack, he had the documents ("identity") which would become evidence and clues in the event of a suicide if he had chosen death.

9. Recurrent thoughts of death (not just the fear of dying), recurrent suicidal ideation without a clear plan or suicide attempt or planning a suicide. He had two suicide attempts (with plan and ideation).

B. Symptoms cause clinically significant discomfort or deficit in social, professional, and other important areas of functioning.

C. The episode cannot be attributed to the physiological effects of a substance or other medical condition. [Association (2013) ].

\subsection{DIFFERENTIAL DIAGNOSIS}

The differential diagnosis is major endogenous depressive episode in a recurrent depressive disorder

Arguments for this diagnosis: according to ICD 10 (1998), recurrent depressive disorder is characterized by repeated episodes of depression, and this category should be used even if there is evidence of short periods of mild mood swings and hyperactivity that meet the criteria of hypomania following a depressive episode.

The patient may have repressed his sadness by using irritability as a defence mechanism.

He has had two suicide attempts so far. The first attempt remained in the ideational plan, failing to put it into practice, and the second resulted in his emergency hospitalization in the admissions room.

The beginning of the first episode appears in the 5th decade of life.

Arguments against: so far, no more than two major depressive episodes in the patient's life are clearly distinguished, although it is not excluded that they will continue afterwards.

Women are twice as likely to suffer from persistent depression as men.

The risk that a patient with recurrent depressive disorder will have an episode of mania in the future never completely disappears, no matter how many depressive episodes there have been. If they occur, the diagnosis will change to bipolar disorder. Lăzărescu et al. (1998). 


\subsection{HYPERTHYMIC PERSONALITY STRUCTURE}

Karl Leonhard (1978) proposed a model of the features of accentuated personalities, among which is the hyperthymic nature. The hyperthymic personality structure is characterized by a surplus of energy that needs to be used, manifesting itself as an accumulation of optimism, joy, desire for action and the need to speak. A negative stress can lead to irritability, superficiality, sterile agitation, etc. Leonhard (1979)

Arguments for: It is possible that throughout his life he exaggerated his positive side in everything that characterized him until the moment when he lost control of his personal life, choosing to neglect it until the moment when he could no longer control anything. "I'm combative, but also soft when I shouldn't (...) Poor communication between me and my wife." Thus, the major depressive episode may have occurred amid this stress, realizing that he may lose his wife and his family will fall apart.

Arguments against: this hypothesis requires a long time to monitor the patient to collect as much data as possible.

\subsection{CONSCIOUS SIMULATION}

Arguments for: The patient was motivated by the stress of a possible imminent separation. He seems to have a fairly high IQ and looking for more ways to solve this marital breakup and failing at the same time, he found one last solution - being the most radical, but not intending to complete it. He tried taking pills for the first time. For reasons we do not know, his wife stole them. It is very possible that he constantly stressed to her that he intended to commit a decisive act in this way and that, as a result, she had taken precautionary measures. The fact that he was hospitalized means he completed his plan and now his wife is afraid of not being responsible for his suicide; even if she no longer wants to stay in the marriage, she will continue for a little while longer.

Arguments against: simulation is common in justice and military circles, quite unusual in normal civilian life. Suicide or intent is an emergency and should not be neglected. The fact that there is a suspicion of a simulation, does not exclude the provision of immediate medical services and observation.

\section{CONCLUSION}

\subsection{SUICIDE PREVENTION}

Mental According to the National Institute of Mental Health, suicide is defined as a death caused by self-inflicted and intentional harmful behaviour. A suicide attempt is defined as non-fatal behaviour with the intent to die. Suicidal ideation refers to thinking, planning, or considering the suicidal act.

The prevalence of suicide over a 20 -year period in the U.S. has increased by $35 \%$. In 2018, the suicide rate among men was $3.7 \%$ higher than that among women Suicide (2021). 
WHO (2014) estimated that worldwide, over 800,000 people die by suicide and that there are many attempts until the person succeeds in this action. Specifically, every 40 seconds, a person commits suicide. This act has a devastating impact on their families, even long after their loved ones have died. Unfortunately, at the moment, suicide is not a major public health problem, despite the fact that research in this area has increased, at the same time the knowledge about prevention is wider Saxena et al. (1981). The taboo and stigma surrounding suicide still persist, and people with problems no longer seek help, and if they do, many health systems fail to provide effective and timely help (Saxena et al., 2014).

Suicide prevention is a systematic way to develop a national response by creating a national prevention strategy. In other words, a clear commitment by the government to solve the problem of suicide. National strategies refer to surveillance, media restriction, media orientation, reducing stigma and raising public awareness Saxena et al. (1981).

Suicide prevention requires a vision, a set of strategies and a specific cultural plan that works in each country. The following factors are needed to create social change: a social strategy (e.g., a national response to achieving suicide prevention goals), knowledge and public support (implicitly political) Saxena et al. (1981).

\section{REFERENCES}

Association, A. P. (2013). Diagnostic and statistical manual of mental disorders: DSM-5. In A. P. Association (Ed.), . Author.

Lăzărescu, M., Teodorescu, R., \& Petrescu, R. (1998). ICD-10 classification of mental and behavioral disorders: Symptomatology and clinical diagnosis. In and others (Ed.), .

Leonhard, K. (1979). Accentuated personalities in life and in literature. (II). Scientific and Encyclopedic Publishing House. In and others (Ed.), . II). Scientific and Encyclopedic Publishing House.

Saxena, S., Krug, E. G., \& Chestnov, O. (1981). Preventing suicide: A global imperative. World Health Organization. The Journal of the American Academy of Psychoanalysis, 9(1), 12951.

Suicide, M. H. I. (2021). National Institute of Mental Health. Mental Health Information. Suicide. 